Provided for non-commercial research and education use. Not for reproduction, distribution or commercial use.

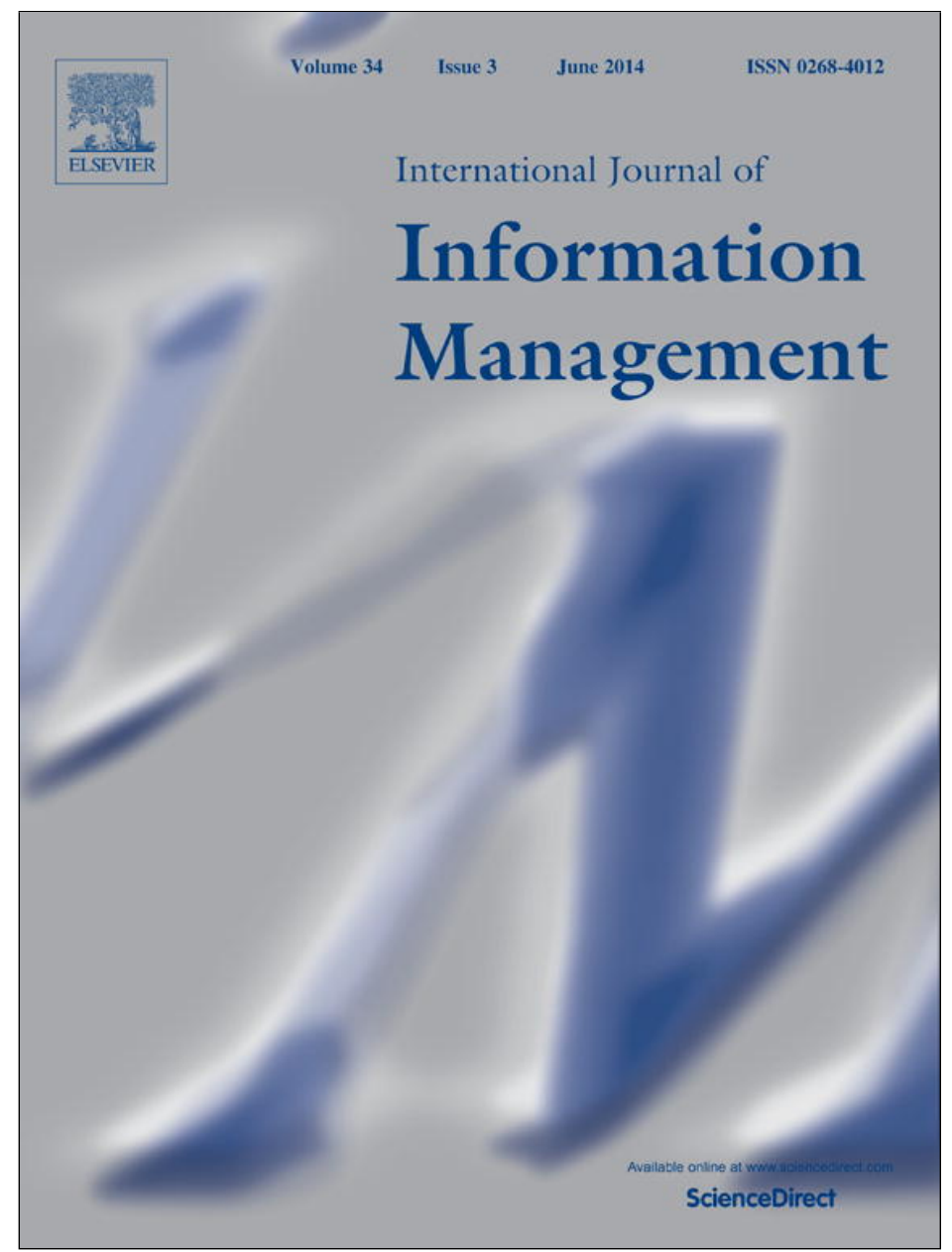

This article appeared in a journal published by Elsevier. The attached copy is furnished to the author for internal non-commercial research and education use, including for instruction at the authors institution and sharing with colleagues.

Other uses, including reproduction and distribution, or selling or licensing copies, or posting to personal, institutional or third party websites are prohibited.

In most cases authors are permitted to post their version of the article (e.g. in Word or Tex form) to their personal website or institutional repository. Authors requiring further information regarding Elsevier's archiving and manuscript policies are encouraged to visit:

http://www.elsevier.com/authorsrights 


\title{
Organizational identity challenges in a post-merger context: A case study of an information system implementation project
}

\author{
Dragos Vieru $^{\mathrm{a}, *}$, Suzanne Rivard ${ }^{\mathrm{b}}$ \\ a École des sciences de l'administration, Tele-University of Quebec, Montreal, QC, Canada \\ ${ }^{\mathrm{b}}$ Information Technologies Department, HEC Montreal, QC, Canada
}

\section{A R T I C L E I N F O}

\section{Article history:}

Available online 26 February 2014

\section{Keywords:}

Organizational identity

Information system implementation

Post-merger integration

Sensemaking

\begin{abstract}
A B S T R A C T
This study examines the effects of the differences in organizational identities that emerged during a postmerger project that aimed at unifying the laboratory services of a large healthcare center that resulted from the merging of three hospitals by supporting them with a unique information system. We draw on the concepts of organizational identity and sensemaking to analyze the laboratory information system implementation project. Organizational identity is conceptualized as the mental representation that organizational members have of themselves as a social group in terms of practices, norms, and values and how they understand themselves to be different from members of other organizations. Data analysis suggests that divergent organizational identities and team members' alternative interpretations of others' practices, norms and organizational symbols, coexist during the post-merger integration phase. These interpretations are reflected in the final functionality of the information system that was different from the planned one.
\end{abstract}

(c) 2014 Elsevier Ltd. All rights reserved.

\section{Introduction}

A merger is the result of a strategic decision aimed at increasing an organization's market share, reducing its costs, or creating synergy (Puranam, Singh, \& Chaudhuri, 2009). Post-merger integration (PMI) is the process of planned value-creation that will hopefully materialize when the organizations are amalgamated (Larsson \& Finkelstein, 1999). All mergers do not imply the same degree of integration among the merging parties or the same degree of autonomy retained by each (Marks \& Mirvis, 2001). At one extreme, the status quo is preserved in each organization. At the other extreme, one party requires the others to adopt its practices, norms, and culture. It may also happen that organizations are gradually combined by enforcing operational interdependence and a common culture, or that an organizational structure and work practices are implemented that are new to all parties. There exist four generic PMI approaches (Ellis, 2004). Preservation refers to a situation where the old boundaries between the merging organizations remain intact. Absorption occurs when one of the firms imposes its work practices, norms and culture on the other parties. Symbiosis represents the integration approach in which the merging parties are gradually blended together by becoming increasingly interdependent and

\footnotetext{
* Corresponding author at: École des sciences de l'administration, Distance Learning | Tel.:e-University of Quebec, 5800, St-Denis Street, Suite 1105, Montreal, QC H2S 3L5, Canada. Tel.: +1 $5148432015 \times 2824$.

E-mail address: dragos.vieru@teluq.ca (D. Vieru).
}

retaining the best parts of each organizational structure. Transformation reflects the situation in which organizations are integrated by developing totally new best work practices and a common organizational identity.

Despite the expected benefits of a merger, PMI is often plagued by problems such as employee stress, dissatisfaction, and resistance (Greenwood, Hinings, \& Brown, 1994). The literature suggests that these problems arise because of perceptions of inter-group differences (Jetten, O'Brien, \& Trindall, 2002), incompatible organizational cultures (Riad, 2005), feelings of exclusion (Harwood \& Ashleigh, 2005), and organizational identity ambiguity (Corley \& Gioia, 2004; van Dick, Ullrich, \& Tissington, 2006). All these problems seem to refer to one core phenomenon: that during PMI, members of the new organization resulting from the union of previously independent entities may feel that their core organizational values and practices are endangered by the inculcation of a new organizational identity.

In addition to the merging of departments, processes and functions, a merger implies the implementation of new information systems (IS) that will span the boundaries of the previously independent organizations (Wijnhoven, Stegwee, \& Fa, 2006). Research has shown, albeit not in a PMI context, that the success of IS implementation projects is highly dependent on effective collaboration among individuals in different professional communities (Levina \& Vaast, 2005; Suchman, 2002). Given the difficulties that plague the PMI process, collaboration is likely to be challenging since the actors involved abide by different local, social, and cultural rules founded in different organizational contexts (Schweizer, 2005). 
Organizational contexts can be defined by the concept of organizational identity (Clark, Gioia, Ketchen, \& Thomas, 2010). Organizational identity represents the ensemble of perceptions shared by organization members about whom they are as an organization (Gioia, 1998). Organizational identity offers the means with which members assign meanings to their daily practices and it is influenced by their beliefs "which are grounded in and interpreted using cultural assumptions and values" (Hatch \& Schultz, 2002, p. 25). Identity formulation represents a "sensemaking" process that allows organizational members to overlay new events on top of past experiences, and to meaningfully interpret and incorporate new information into a frame of explanatory reference (Weick, Sutcliffe, \& Obstfeld, 2005) that might be useful for purposes of enhancing future predictability, such as what to expect from a daily collaboration with new colleagues from merging entities.

During organizational change, organizational identity is often susceptible to change (Dutton \& Dukerich, 1991; Vaara, 2003) and existing knowledge bases become inadequate and need to be changed (Nag, Corley, \& Gioia, 2007). Therefore, collaboration across knowledge boundaries, symbolic representations of organizational identities, and specific degrees of integration imposed by the upper-management of an organization during the PMI phase, are likely to be continually negotiated in a process that involve multiple relationships at different levels of analysis (Clark et al., 2010). The dynamics of collaboration-identity during IS implementation efforts in a PMI context, in particular, have seen no empirical research. Thus, this article addresses a notable gap in the IS literature. Given this, our main research question is:

How do differences in organizational identities among team members engaged in collaboration during IS implementation in PMI influence the resulting IS functionality?

In this study, we aim to understand the challenges encountered when an IS is implemented to support an organization that emerges from a merger. To do this, we draw on the literature on organizational identity (Albert \& Whetten, 1985; Clark et al., 2010) and on the "sensemaking" perspective (Weick et al., 2005) to analyze an IS implementation project in a large teaching healthcare center resulting from a merger. Our analysis suggests that divergent organizational identities, which with team members' alternative interpretations of others' practices, norms and organizational symbols, coexist during PMI at different levels of analysis. Thus, we propose a multi-level process model based on two motors of change: teleological and dialectic (Van de Ven \& Poole, 1995). This model suggests that the relationship between IS project team members' collaboration and their different organizational identities at the individual level has an effect on the integration approach decision at the organizational level.

\section{Theoretical background}

\subsection{Organizational identity}

Most of the literature on organizational identity develops the idea that identity is a dynamic construct formed in interaction with organizational image (Dutton \& Dukerich, 1991; Gioia, 1998) and organizational culture (Hatch \& Schultz, 2002; Ravasi \& Schultz, 2006). Organizational identity constitutes mental representations of how organizational members define themselves as a social group in terms of practices, norms, and values and understand themselves to be different from members of other organizations. At the individual level, it reflects the shared understanding of what the organizational norms, values, and practices are (Albert \& Whetten, 1985). At the organizational level, identity can be reified as an organizational asset, something that is durable or can be illustrated as a dynamic process, something that is continuously in a "becoming" phase formed by the amalgamation of the distinctive attributes of individuals (Clark et al., 2010). Through continuous interaction, organizational members reconstruct their organizational identity through interpretive schemes in order to provide meaning to their experiences and practices as part of their membership to a specific organization (Dutton, Dukerich, \& Harquail, 1994). The more an individual conceives of the self in terms of the membership of an organization, the more the individual's attitudes and behavior are governed by this organization membership (Hogg \& Terry, 2000).

The dynamic nature of the organizational identity is reflected by its recurrent link with organizational culture. A number of scholars recognize the need to make a distinction between the organizational culture and identity (e.g., Fiol, 1991; Hatch \& Schultz, 2002). Organizational culture provides a symbolic context within which perceptions of organizational identity are formed (Hatch \& Schultz, 2002); thus, identity is part of the belief system (culture) by which organizational members make sense of their actions. Consequently, identities represent the behavioral expressions of the aspects of organizational culture interpreted in a specific context (Fiol, 1991).

Complex changes such as spin-offs and mergers trigger a process of change of the organizational identity (Corley \& Gioia, 2004). Therefore, identity can also be understood as a dynamic process rather than just a static organizational asset (Clark et al., 2010). Existing studies suggest that successful major organizational changes are linked to a change in organizational identity (e.g., Corley \& Gioia, 2004; Dutton \& Dukerich, 1991; Gioia, 1998). Overall these studies clearly point to the fact that the relationship between organizational identity and change is a dynamic process laden with uncertainty and that members' interpretive schemes have an impact on any attempt to change identity.

\subsection{Post-merger organizational identity "sensemaking"}

An organization's identity could be regarded of as a set of "negotiated cognitive images" that emerge out of "complex, dynamic, and reciprocal interactions" (Scott \& Lane, 2000, p. 43) among people who are both internal and external to the organization. Issues of change in organizational identity arise as an organization attempts to answer the question "Who are we?" Organizational identity is reconsidered and reconstructed through processes of sensemaking (Weick et al., 2005) as organization members confront the knowledge and implications of others' views of the organization (e.g., views of members from the different merging organizations). In this vein, in our study we are interested in how members of merging organizations make sense of their pre-merger organizational identity by assessing it during collaboration initiatives in the emerging context of PMI.

Sensemaking is defined as the development of ongoing retrospective meanings of what individuals are doing in an organizational context (Weick, 1995). Although sensemaking is an ongoing process, the need to make sense is intensified in circumstances where organizational members face situations where there is no predetermined way to act, and where a high degree of ambiguity is experienced (Weick et al., 2005). Relevant to this study, a merger most probably will change organizational members' current work practices. This type of situation might cause a 'shock' that triggers an intensified period of sensemaking (Weick, 1995), which informs action.

Organizational identity construction and the use of plausibility are the two basic properties of sensemaking (Gililand \& Day, 2000). Weick et al. (2005) suggest that the "stakes in sensemaking are high when issues of identity are involved" because "who we think we are (identity) as organizational actors, shapes what we enact and how we interpret" (p. 416). Thus, sensemaking is more about plausible interpretations and expectancies, than about truth, accuracy 
or getting things right. In the context of PMI, individuals will use their interpretations of organizational identity as a guidepost for measuring the importance of the changes in their work practices that the merger might bring. They will also make sense of what to expect from their new colleagues based and their interpretation of the others' organizational identity.

\subsection{Cross-boundary collaboration in IS implementation}

We adopt a dynamic view of cross-boundary collaboration during projects, such as the implementation of new IS in PMI context, that emphasizes that relevant knowledge is created and shared in social interactions (Orlikowski, 2002). Here, knowledge is defined as multi-faceted and complex, being situated and abstract, tacit, and explicit. This approach advances the idea that in order to understand how knowledge is created, articulated, disseminated, and legitimized within organizations, knowledge should be considered as being an individual disposition embedded in organizational structures and in the social relationships evolving among the members of the same organization (Orlikowski, 2002).

Sharing knowledge among people who are members of different organizations is difficult, since they usually do not share the same set of values, ideas, and interests. This makes tacit knowledge easy to move within groups who have similar identities in terms practices and norms, but difficult to shared across groups who have diverse organizational norms and values (Brown \& Duguid, 2001). Sustained inter-organizational collaboration often leads to organizational boundaries that are based on different organizational identities or the choice of "who we are" (Santos \& Eisenhardt, 2005). Thus, knowledge bases within the same organizational boundaries of identity allow for efficient communication within the group at the expense of making communication and understanding difficult for outsiders.

\subsection{Post-merger integration as a multilevel process of organizational change}

Organizations are multilevel phenomena (Tsoukas \& Chia, 2002) and, therefore, IS-driven organizational change (such as the implementation of a cross-boundary IS in a PMI context) is best outlined as a process theory that takes into consideration how processes at different levels of analysis shape each other (Poole \& Van de Ven, 2004). A process theory explains how a sequence of events that unfolds through time leads to some outcome and can provide explanations on how one micro-level event leads to and affects the ensuing one (Van de Ven \& Poole, 1995). It can also shed light on how a macro-level pattern may trigger the succession of micro-level events. In this viewpoint, the IT-driven organizational change represents a process that entails a "sequence of individual and collective events, actions, and activities unfolding over time in context" (Pettigrew, 1997, p. 337). A processual approach to analyze organizational change provides a rich and detailed story of the events taking place within a specific organizational context (Langley, 1999). In the context of a merger, a process theory illustrates how influential factors interact, such as user perceptions, organizational identity, IT functionality, and the nature of existing knowledge bases, how they collectively trigger human agency, and what constrains them.

Important change processes in organizations, such as the introduction of a new IS that significantly changes daily practices can be explained over time by four different theories of change or "motors": life-cycle, teleology, dialectic, and evolutionary (Van de Ven \& Poole, 1995). Life-cycle and evolutionary are prescribed modes of organizational development and change because the process unfolds in a pre-established order; teleology and dialectic are constructive modes of change as the development is discontinuous and unpredictable. Moreover, life-cycle and teleology depict the development and change of a single organizational entity, while evolutionary and dialectic depict multiple organizational entities.

With regard to the implementation of a cross-boundary IS in a PMI context, the multilevel process of IS-driven organizational change is clearly governed by a dual motor: one at the individual level and another at the organization level. At the individual level, each individual makes sense of the technology that would enable organization-based norms and practices. The individuallevel decisional events influence further how decisions are taken at the organization level, such as a specific post-merger integration approach that would be reflected by the functionality of an IS. Moreover, organization level events shape those individual mental frameworks given the reciprocal influence between individuals' perceptions and the social and historical context in which they developed over time (Orlikowski, 2002).

\section{Methodology}

This research was conducted as a case study in order to better understand the underlying dynamics of the phenomenon studied (Yin, 2003). We chose an implemented IS project within one organization that was engaged in the process of post-merger integration. The selected organization was the Teaching Health Centre (THC - not a real name), a Canadian tertiary care teaching institution. The THC is the result of a "merger of equals" of three independent teaching hospitals: two Adult hospitals (the Downtown and the Midtown) and the Pediatric hospital. The THC was created with the clear goal to provide a "best practices" business model for coordinating care.

Although studies have shown that the participants in organizational processes do not forget key events in these processes, it is possible that a participant-informant in a retrospective study may not have judged an event as important when it occurred and therefore may not remember it later (Leonard-Barton, 1990). To avoid these shortcomings, we obtained access to a number of emails that team members exchanged during the IS implementation. We also followed Leonard-Barton's (1990) recommendation to engage in informal conversations (e.g., at lunch or in hallways) with individuals who were members of the project team because useful data may emerge from this type of interaction.

We conducted semi-structured interviews with the persons who had held key roles in the project. The interviews were supplemented by archival documents (e.g., strategic planning sessions, management presentations, and communications planning), which offered a source of triangulation for the themes that emerged from the interview data. The interviewees were selected following a snowball sampling procedure. A total of 15 interviews were performed. Interview questions focused on understanding, from the participant's standpoint, the history of the project collaboration practices, differences in identities, differences in IS' functionalities between the initial and the go-live phases of the project. When no new information was revealed during interviews, data collection was terminated.

The interview data were analyzed in an iterative process (Eisenhardt \& Graebner, 2007). We cycled between data, emerging themes, and relevant literature to develop a deeper understanding of the dynamics of the IS implementation process. We first wrote the case by synthesizing the interview transcripts. During case analysis, themes emerged from the data. Coding was a twostage process. In Stage 1 we created a provisional "start list" of codes prior to the interviews. Most of the initial coding categories were based on the concepts of organizational identity (Clark et al., 2010) and on the four ideal PMI approaches (Ellis, 2004). In Stage 2 , the interview transcripts were introduced into a database, read carefully, and relevant portions highlighted as "evidence". 


\section{Findings}

\subsection{The laboratory information system (LIS) project}

In 2002, upper management decided to implement a new, unique across the sites, laboratory information system (LIS), a technological platform provided by the company Sigma. This would would improve the quality of patient care by providing comprehensive overall functionality, accessibility to data throughout the THC. In general, the role of an LIS in a hospital is to automate laboratory clinical, financial, and managerial processes and to allow laboratory staff to establish and maintain accurate tracking, processing and recording of results, while avoiding lost and misplaced specimens. Even though this description of a typical medical laboratory workflow seems to be quite straightforward, the three site-based laboratory services at THC were using three different workflows and had different legacy ISs.

At the outset of the project, THC upper management proposed guidelines for the standardization of the practices of the three main laboratories. The entry of lab requests involves typing or scanning (where barcodes are used) of the laboratory number, and entering the patient identification, which gives a destination (hospital department/physician) for results to go.

The LIS implementation project team was composed of a number of lab technologists, physicians, and IS specialists with experience in clinical applications. During Phase 1 of the project, the lab physicians from the three sites, who struggled to find common grounds for establishing unique workflows, tried to accommodate as many old procedures and workflows as the new LIS would accommodate. At the end of 2004, Sigma advised THC that it would provide a new version of their LIS platform that would force the LIS team members to start the process of building the database of the system from scratch. This was seen as an opportunity by the upper management to put pressure on the clinicians to reach an agreement on common lab procedures. Phase 2 of the project concluded in September 2005, when the new LIS based on common lab practices was put into production at the Downtown site, followed by Midtown and Pediatric sites in February 2006. While the initial design was based on best practice standards, the final configuration revealed a blend of industry standards (transformation approach) and local pre-merger contingencies (preservation approach).

\subsection{Theme 1: "us versus them"}

At the outset of the Phase 1, there were three-site based sets of lab procedures: the Midtown site, the Downtown site, and the Pediatric site:

"We had Downtown working one way, Midtown working another way, Pediatric working a different way. That was like 'Joe' works at this bench. 'Jim' works on the same bench; he's going to work on what he thinks on that bench. You take those two people that have different visions of doing the same work and multiply it by three sites." (Lab technologist Downtown)

"Because we were only going to have one LIS, we had to have a common set of how we were going to work up the workflows, the practices that had to have common protocols, which we did not have before. Like, the Downtown would have their own protocols, the Midtown, the Pediatric; so in fact it was a forced method in making us have common protocols." (Microbiologist Midtown)

In these conditions, collaboration was not possible before team members understood the differences between the practices of the three lab services at the end of Phase 1 . In Phase 2, while trying to negotiate common procedures, team members from the
Adult sites engaged in discourses that overstated the differences in practices and norms between their sites and tried to convince the other members how much better one lab was over the other ones:

"The Midtown was always a more efficient lab of the three sites. The Downtown was very specialized in all kinds of esoteric testing. They were not as efficient as the Midtown was." (Lab services Director Midtown)

"When you talk to the Midtown people they will tell you they are more efficient than the Downtown and at the Downtown the staff don't know what they are doing, etc." (Pathologist Downtown)

The evidence points to the fact that these discourses of "usversus-them" were part of the "war" between the two Adult sites, an ongoing process of justification of why each site was unique and had different needs than the other sites during the IS implementation processes. This situation shed light on the existence of a continuing struggle to impose one organization identity as being dominant over and against the other competing alternative. Even though the merger was announced in 1998, the boundaries around the pre-merger hospitals continued to exist in the mind frames of the individuals during the IS implementation process. Thus, the ever-present competitiveness among the three main THC sites, the perpetuation of the pre-merger organizational identity with an emphasis on the differences between members of the different merging entities, allowed decisions at the THC organization level to be acknowledged but differently applied at the department or group level. The data suggest also that team members use their sensemaking of organizational identity as a reference for evaluating the changes in their practices that the merger might bring.

The LIS technological platform was conducive to both imposing new practices (lab requests and access to results) and preserving some pre-merger practices (order entry). Thus, after the implementation, the LIS unified all laboratory protocols across the sites and linked the laboratories in one common system. Also, the laboratories had to change how their staff were managing the laboratory requests because the LIS imposed one set of common practices. However, at the same time, the LIS made it possible for the Pediatric site to keep its pre-merger order entry procedures and for a number of lab technologists from the Adult sites to use workarounds to accommodate some pre-merger practices.

“[The Pediatric site] still doesn't have order entry on the floors. So they're getting the samples the same way as they always got them. They didn't standardize the way they work to our way." (Midtown laboratory manager)

"We thought that there was one way of working with the system. But a year after implementation [2007], we did a follow up and we found that some people were having problems with the functionality and that they [the laboratory staff] resolved it. So we found out that there were different practices... workarounds, depending on the problem." (Downtown laboratory manager)

Our analysis suggests that the sensemaking-based symbolic discourses of 'us-versus-them', influenced the final outcome of the IS implementation. While the planned IS functionality design reflected a PMI transformation approach, the final IS functionality reflected a trade-off between the initial design for new practices and site-based pre-merger practices (preservation). Taking into consideration the above argumentation we advance a first research proposition:

P1. Processes of sensemaking of "us-versus-them" will affect the outcomes of the post-merger IS implementation project in a way that the final IS functionality will differ from the planned one. 


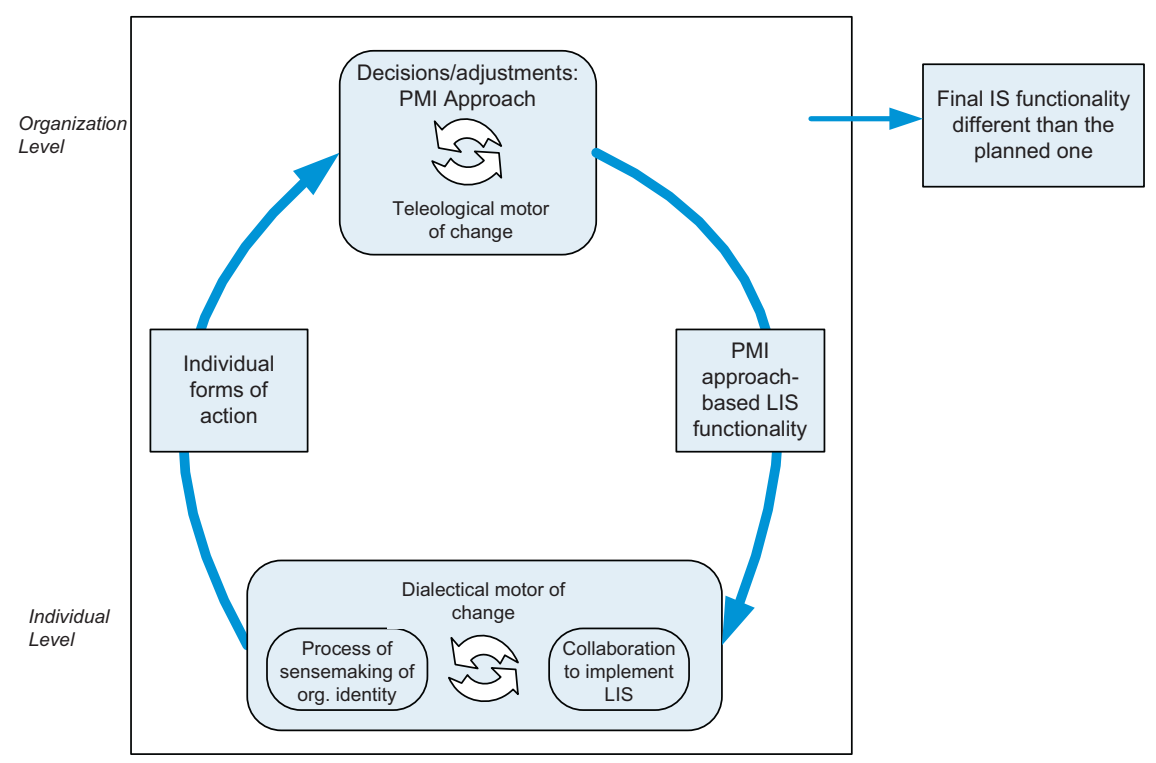

Fig. 1. A dual motor multilevel process of post-merger IS implementation.

\subsection{Theme 2: enduring nature of the old organizational identities}

Some of the team members saw the implementation of the new LIS as a means to reify their loss of organizational identity. Some of the excerpts of the interviews reflect this fact:

“They didn't give us a chance to mourn [...]. We were losing the identity that we had as standalone areas." (Lab technologist Downtown)

"The overall consequence was the loss of institutional identity." (Physician Midtown)

To resist the emergence of a new identity common across the site boundaries, team members tried to perpetuate the old organizational identities, even though in some cases this was counterproductive for everybody at the THC.

"The culture within THC has always been three hospitals for them, and it's very difficult to be able, even at the level of directors, to make them understand that when we compete against [other healthcare institutions] we need to work together." (Microbiologist Midtown)

Each pre-merger organizational identity was based on common beliefs about the value of their contextual practices, of what was "at stake". Thus, the evidence suggests that when members showed little interest in the others' "stakes", the project didn't advance well and eventually stalled (Phase 1 ). Only when pressured by the upper management (Phase 2), did the team members learn to acknowledge and understand the others' rules and values that eventually led them to realize that trade-offs were available for them.

The data analysis revealed that the interviewees considered that there was a rationale for each different set of practices. Their comments reflect the existence of separate contextual meanings and organizational symbols at each of the three hospital sites. The individuals, as members of the same pre-merger organization, shared an identity, which was based on an agreement on what was at "stake" in each organization. Thus, the effective collaboration happened only after individuals started to acknowledge and understand that different "stakes" needed to be taken into consideration during the process of negotiation of common interests. For instance, when the team members had no interest understanding the other different sets of norms and values, the project came to a standstill (Phase I). Based on the above argumentation, we advance a second research proposition:
P2. Acknowledging and understanding the reason for each set of different organizational identity-based norms and values will enable team members to effectively collaborate during IS implementation in a PMI context.

4.4. Theme 3: organizational identity sensemaking and PMI approaches - a dual motor process model

The findings suggest that at the individual level, individuals' actions were formulated by their sensemaking of their pre-merger organizational identity based on different norms, values and organizational symbols. For example, the physicians from the three labs were trying to maintain the old lab norms unaltered by demanding the IS would reflect their old practices.

“There was [this] 'keeper' of the knowledge mentality and tried to gather this information was difficult [...] There was very little cooperation from the physicians that were on the team. They wanted to make sure that they could maintain their own little kingdoms." (Lab technologist Downtown)

These individual actions were the product of the interplay between opposing forces: the sensemaking of the organizational identity and the collaboration needed during the project to implement the planned functionality of the LIS. Thus, it can be inferred that the mechanism for driving change at the individual level is dialectical (see Fig. 1), following colliding forces and contradictory values that compete with each other (Van de Ven \& Poole, 1995). The proposed model operates at two levels: the organization (management decided to implement a common LIS that would reflect a transformation PMI approach - teleological motor) and the individual (team members' struggled to defend their old lab procedures based on processes of sensemaking of organizational identity - dialectical motor). The outcome of the IS implementation was an IS that enabled a main set lab practices and accommodated the particularities of the Pediatric site and some 'workaround' procedures at the Adult sites (decisional adjustment - mix of transformation and preservation). Thus, the initial functional design of the IS that reflected practices related to a specific PMI approach (transformation) was different from the final functionality at the end of the IS implementation process. Thus, we propose a third research proposition: 
P3. Individual sensemaking processes of organizational identity corroborated with the decisional adjustment of the PMI approach will shape the final functionality of the new information system.

\section{Conclusions and future research}

The case data analysis revealed that while the planned postmerger integration approach was a transformation, the outcomes of the project suggest a mix of preservation and transformation. Our study makes a number of contributions. In terms of practical implications, this research emphasizes that while it is paramount to develop and implement ISs with functionalities that enable post-merger practices, management would be in a better position to make a decision regarding the integration approach if it understood the why similar business processes were performed differently in the previously independent organizations. In terms of contributions to information systems research, first, by using the concept of organizational identity we were able to see that the final functionality of the implemented IS reflected individuals' understandings of the others' norms, values and organizational symbols. Second, we developed a dual motor process model that provides an explanation of how organizational-level decisional events, such as the choice of PMI approach, impact on how the functionality of new ISs will be implemented at an individual level, and how those organizational-level events, in turn, are shaped by the individual level events and effects.

THC was a unique setting in many respects and it would be fruitful if future research continues building the theory developed in this study based on data from other PMI settings in different industries. Mergers as a popular form of radical change are now ubiquitous and stakeholders typically support a merger because it should create new synergies. However, the actual integration of merging entities is challenging, even when strategic and economic arguments make a persuasive case for merging. This study suggests that analyzing mergers in terms of the required identity change should constitute food for thought for researchers interested in gaining further insights into the dynamics of radical organizational change.

\section{References}

Albert, S., \& Whetten, D. (1985). Organizational identity. In L. Cummings, \& B. Staw (Eds.), Research in organizational behavior (70) (pp. 263-295). Greenwich: JA Press.

Brown, J. S., \& Duguid, P. (2001). Knowledge and organization: A social-practice perspective. Organization Science, 12(2), 198-213.

Clark, M. S., Gioia, D., Ketchen, D. J., Jr., \& Thomas, J. (2010). Transitional identity as a facilitator of organizational identity change during a merger. Administrative Science Quarterly, 55(3), 397-428.

Corley, K., \& Gioia, D. (2004). Identity ambiguity and change in the wake of a corporate spin-off. Administrative Science Quarterly, 49(2), 173-208.

Dutton, J., \& Dukerich, J. (1991). Keeping an eye on the mirror: Image and identity in organizational adaptation. Academy of Management Journal, 34(3), 517-554.

Dutton, J., Dukerich, J., \& Harquail, C. (1994). Organizational images and member identification. Administrative Science Quarterly, 39(2), 239-263.

Eisenhardt, K., \& Graebner, M. (2007). Theory building from cases: Opportunities and challenges. Academy of Management Review, 50(1), 25-32.

Ellis, K. (2004). Managing the acquisition process: Do differences actually exist across integration approaches. In A. L. Pablo, \& M. Javidan (Eds.), Mergers and acquisitions: Creating integrative knowledge (pp. 113-132). Oxford, UK: Blackwell

Fiol, M. C. (1991). Managing culture as a competitive resource: An identitybased view of sustainable competitive advantage. Journal of Management, 17(1), 191-211.

Gililand, S. W., \& Day, D. (2000). Business management. In F. T. Durso (Ed.), Handbook of applied cognition (pp. 315-342). New York: Wiley.

Gioia, D. A. (1998). From individual to organizational identity. In D. A. Whetten, \& P C. Godfrey (Eds.), Identity in organizations: Building theory through conversations (pp. 17-32). Thousand Oaks: Sage.

Greenwood, R., Hinings, C. R., \& Brown, J. (1994). Merging professional service firms Organization Science, 5(2), 239-257.

Harwood, I., \& Ashleigh, M. (2005). The impact of trust and confidentiality on strategic organizational change programmes: A case study of post-acquisition integration. Strategic Change, 14(2), 63-75.

Hatch, M. J., \& Schultz, M. S. (2002). The dynamics of organizational identity. Human Relations, 55(8), 989-1019.
Hogg, M. A., \& Terry, D. J. (2000). Social contextual influences on attitude-behavior correspondence, attitude change, and persuasion. In D. J. Terry, \& M. A. Hogg (Eds.), Attitudes, behavior, and social context: The role of norms and group membership (pp. 1-9). Mahwah, NJ: Erlbaum.

Jetten, J., O’Brien, A., \& Trindall, N. (2002). Changing identity: Predicting adjustment to organizational restructure as a function of subgroup and superordinate identification. British Journal of Social Psychology, 41(2), 281-297.

Langley, A. (1999). Strategies for theorizing from process data. Academy of Management Review, 24(4), 691-710.

Larsson, R., \& Finkelstein, S. (1999). Integrating strategic, organizational, and human resource perspectives on mergers and acquisitions: A case survey of synergy realization. Organization Science, 10(1), 1-26.

Leonard-Barton, D. (1990). A dual methodology for case studies: Synergistic use of a longitudinal single site with replicated multiple sites. Organization Science, 1(3), 248-266.

Levina, N., \& Vaast, E. (2005). The emergence of boundary spanning competence in practice: Implications for implementation and use of information systems. MIS Quarterly, 29(2), 335-369.

Marks, M. L., \& Mirvis, P. H. (2001). Making mergers and acquisitions work: Strategic and psychological preparation. Academy of Management Executive, 15(2), 80-94.

Nag, R., Corley, K. G., \& Gioia, D. A. (2007). The intersection of organizational identity, knowledge, and practice: Attempting strategic change via knowledge grafting. Academy of Management Journal, 50(4), 821-847.

Orlikowski, W. J. (2002). Knowing in practice: Enacting a collective capability in distributed organizing. Organization Science, 13(3), 249-273.

Pettigrew, A. (1997). What is processual analysis? Scandinavian Journal of Management, 13(4), 337-348.

Poole, M. S., \& Van de Ven, A. (2004). Theories of organizational change and innovation processes. In M. S. Poole, \& A. H. Van de Ven (Eds.), Handbook of organizational change and innovation (pp. 374-397). NY: Oxford University Press.

Puranam, P., Singh, H., \& Chaudhuri, S. (2009). Integrating acquired capabilities: When structural integration is (un)necessary. Organization Science, 20(2), 313-328.

Ravasi, D., \& Schultz, M. (2006). Responding to organizational identity threats: Exploring the role of organizational culture. Academy of Management Journal, 49(3), 433-458

Riad, S. (2005). The power of 'organizational culture' as a discursive formation in merger integration. Organization Studies, 26(10), p.1529-p.1554.

Santos, F., \& Eisenhardt, K. (2005). Organizational boundaries and theories of organization. Organization Science, 16(5), 411-491.

Schweizer, L. (2005). Organizational integration of acquired biotechnology companies into pharmaceutical companies: The need for a hybrid approach. Academy of Management Journal, 48(6), p.1051-p.1074.

Scott, S., \& Lane, V. (2000). A stakeholder approach to organizational identity Academy of Management Review, 25(1), 43-62.

Suchman, L. (2002). Practice-based design of information systems: Notes from the hyperdeveloped world. Information Society, 18(2), 139-144.

Tsoukas, H., \& Chia, R. (2002). On organizational becoming: Rethinking organizational change. Organization Science, 13(5), 567-582.

Vaara, E. (2003). Post-acquisition integration as sensemaking: Glimpses of ambiguity, confusion, hypocrisy, and politicization. Journal of Management Studies, 40(4), 859-894.

Van de Ven, A. H., \& Poole, M. S. (1995). Explaining development and change in organizations. Academy of Management Review, 20(3), 510-540.

van Dick, R., Ullrich, J., \& Tissington, P. A. (2006). Working under a black cloud: How to sustain organizational identification after a merger. British Journal of Management, 17(S1), S69-S79.

Weick, K. E. (1995). Sensemaking in organizations. Thousand Oaks, CA: Sage Publications.

Weick, K. E., Sutcliffe, K., \& Obstfeld, D. (2005). Organizing and the process of sensemaking. Organization Science, 16(4), 409-421.

Wijnhoven, F. S., Stegwee, T. R., \& Fa, R. T. A. (2006). Post-merger IT integration strategies: An IT alignment perspective. Journal of Strategic Information Systems, 15(1), 5-28.

Yin, K. R. (2003). Case study research design and methods. Thousand Oaks, CA: Sage Publications.

Dragos Vieru is an assistant professor at Tele-University of Québec. He received his Ph.D. in Information Technology at HEC Montréal. His research interests are in the areas of IT-enabled organizational change, knowledge sharing, and IT governance. Dragos Vieru has published papers in the International Journal of Social \& Organizational Dynamics in Information Technology and in the Lecture Notes in Business Information Processing. He is co-chair of the Organizational and Social Dynamics in Information Technology mini-track at the Hawaii International Conference on System Sciences (HICSS). He has over 15 years of professional experience in IT project management in the healthcare industry.

Suzanne Rivard is the HEC Montréal Endowed Chair in Strategic Management of Information Technology. She received a Ph.D. from the Ivey School of Business at the University of Western Ontario. Her research interests are in the areas of IS development, outsourcing of IT services, and strategic alignment of IT. Suzanne Rivard is a fellow of the Royal Society of Canada. Her work has been published in such journals as Journal of Information Technology, Journal of the Association for Information Systems, Journal of Strategic Information Systems, MIS Quarterly, Organization Science, and others. 